\title{
The effectiveness of ankle foot orthosis on gait in children with spastic diplegic cerebral palsy
}

\begin{abstract}
Introduction: Cerebral palsy is a life lasting disability and is one of the most expensive diseases. CP is defined as a non-progressive, chronic, involuntary movement disorder secondary to an injury or lesion of the immature brain. The lesion usually occurs prenatally on prenatally: only about 10 per cent of the lesions are of postnatal origin. In most patients, a specific cause is not identified. Orthotic management is a widely utilized method of treatment in children with $\mathrm{CP}$ due to its conservative nature. Orthosis continue to have an important role in many therapeutic regimens for children with CP. However; there have been differences in design variants of Orthosis prescribed for the common problem of Spastic Cerebral Palsy. Three AFO configurations frequently prescribed for children with spastic cerebral palsy they are Hinged AFO (HAFO), the Posterior leaf spring (PLS AFO), and the Solid AFO (SAFO).
\end{abstract}

Methods: Thirty subjects with Spasticdieplegic Cerebral palsy aged from 5-15 years with (male $=20$ and female $=16$ ) chosen through randomized sampling and taken in this study. The Selected subjects underwent indicated AFOs (SAFO, PLSAFO, HAFO,). Each intervention was given up to three months with wearing schedule 6-12 hours per day.

Results: Results shows a significant improvement in Gait Parameters i.e. Step length $(p<0.020)$, stride length $(p<0.003)$, cadence $(p<0.005)$, Velocity $(p<0.002)$, but not significant difference in comparison between SAFO, PLSAFO and HAFO.

Conclusion: The findings of the study support the hypothesis that there were significant differences between the three design variants of AFO in improving gait parameters in subject with spasticdieplegic Cerebral Palsy.

Keywords: spastic diplegic cerebral palsy, ankle foot orthosis, gait parameters

\author{
Volume 8 Issue 2 - 2018
}

\section{Dhruti Sundar Das,' Jeetendra Mohapatra,' Prasanna Lenka'}

'Department of Prosthetic \& Orthotic, National Institute for Locomotor Disabilities, India

${ }^{2}$ Department of Occupational Therapy, National Institute for Locomotor Disabilities, India

\author{
Correspondence: Dhruti Sundar Das, Department of \\ Prosthetic \& Orthotic, National Institute for Locomotors \\ Disabilities (Divyangjan), (Previously known as $\mathrm{NIOH}$ ), \\ Kolkata-700090,West Bengal, India, Tel 9088656747, \\ Email dhrutisundardas@gmail.com
}

Received: January II, 2017 | Published: April II, 2018

\section{Introduction}

Cerebral palsy is a syndrome caused by a lesion of the brain; it is characterized by abnormal control of motor function and it may interfere with sensory function and intellectual development. ${ }^{1-4}$ $\mathrm{CP}$ is defined as a non-progressive, chronic, involuntary movement disorder secondary to an injury or lesion of the immature brain. In some cases a cognitive deficit may also be present. ${ }^{5-11}$ The known causes of the syndrome include mal development of the brain, vascular and traumatic insults, toxic substances, metabolic disorders, and infections. The lesion usually occurs prenatally on prenatally: only about 10 per cent of the lesions are of postnatal origin. In most patients, a specific cause is not identified. ${ }^{1}$ The characteristic signs are spasticity, movement disorders, muscle weakness, ataxia, and rigidity. Cerebral palsy is the most common cause of severe physical and motor disability in childhood. ${ }^{12-14}$

The objectives of the treatment are:

a. Decreasing to the minimum of the muscular contractions and bony deformities, by decreasing or even normalizing muscle tone, and increasing joint mobility;

b. Increasing muscular strength on weak muscles;

c. Improvement of mobility and gaining motor functional skills. ${ }^{15}$
Ankle-foot Orthosis (AFOs) are designed to: prevent deformity, support normal joint alignment and mechanics, provide variable range of motion when appropriate, and facilitate function (Rosenthal 1984, Brodke et al. ${ }^{16}$ Knutson et al. ${ }^{17}$ Tecklin 1994). The chief role of the AFO in this application is to limit unwanted ankle and subtler movement, primarily ankle plantar flexion, and indirectly to affect knee and hip function. ${ }^{18}$ Three AFO configurations frequently prescribed for children with spastic cerebral palsy they are hinged ankle foot orthosis Posterior leaf spring (PLS AFO), and the Solid AFO (SAFO). ${ }^{19,20}$ A polypropylene fixed or solid ankle-foot orthosis (SAFO) has been the most commonly prescribed brace for reducing excessive ankle plantar flexion during stance. The SAFO is made of polypropylene that covers the entire posterior calf and the medio lateral borders and sole of the foot, with straps across the anterior upper tibia and front of the ankle. It biomechanically controls the ankle by using a three-force system to prevent excessive ankle plantar flexion during stance. ${ }^{21,22}$ The use of rigid AFOs to ensure the soleus muscle is stretched for more than 6 hours every day has also been suggested as a way to prevent contractures developing. ${ }^{10} \mathrm{New}$ developments in orthotic design that apply a measured and controlled torque over both the knee and ankle joints may perhaps be more effective at correcting contractures. ${ }^{14,23} \mathrm{The}$ Posterior Leaf Spring AFO (PLS AFO), which allows slight plantar flexion as well as dorsiflexion in stance because of its posterior trim line, has been reported to promote 'normal' ankle rocker function and create a more dynamic gait (Ounpuu et al. 1996, Brunner et al. ${ }^{24}$ The Hinged AFO (HAFO), which allows free dorsiflexion in stance phase 
and limits plantar flexion to a pre-set level (usually $90^{\circ}$ ), has been noted to normalize ankle motion during the stance phase of gait and facilitate the performance of developmental motor skills (Middleton et al. 1988, Rethlefsen et al. 1995, Wilson et al. 1997, Rethlefsen et al. 1999).22,23 Using gait analysis, rigid AFOs have been shown to influence directly the extent to which forces act on the body during standing and walking. ${ }^{11,25}$ In his classification of gait patterns in spastic hemiplegic, Winters recommended the more flexible posterior leaf spring (PLS) AFO to prevent equinus only in swing phase, and the rigid $\mathrm{AFO}$ for preventing equinus in the stance and swing phases of gait. ${ }^{23,26}$ More specifically, the goals of orthotic management are to facilitate function by preventing deformity achieve a stable base, improve dynamic efficiency of gait, and, supporting normal joint alignment, by controlling or eliminating ankle and subtler motion to prevent contractures and improve gait by reducing tone and spasticity, improving proprioception and balance. ${ }^{5,18}$ Ankle-foot orthosis (AFO) prescription in children with spastic diplegic is intended to amend the 'typical' diplegic gait pattern characterized by hip flexion, adduction, and internal rotation, knee flexion, and ankle equines with hind foot values (Gage 1991), thus enhancing function.23 Although ankle-foot orthosis (AFOs) are frequently prescribed for ambulatory children with spastic $\mathrm{CP}$, a limited number of investigations have substantiated the effectiveness of orthotic intervention or validated claims made regarding the benefits of different AFO configurations. The purpose of this study was to determine effectiveness three commonly prescribed AFO configurations (HAFO, PLSAFO, SAFO), with, Gait parameter's, in ambulatory children with spastic diplegic.

\section{Materials and method}

In order to meet the purpose of the study a planned and careful procedure was chosen before proceeding further. A sample of 36 subjects were chosen through randomized sampling with (male $=20$ and female=16) diagnosed with Spasticdieplegic Cerebral palsy were referred from NIOH OPD, The study protocol was approved by Institutional Ethical Committee and conducted in lab of National Institute for the Orthopedically Handicapped, Kolkata, India. all participants were requested to sign an informed consent form, age group between 5-15 years who were capable of independent ambulation without assistive devices and not undergone any Orthopedic and neurosurgical intervention in preceding year, Except physiotherapy and occupational therapy After screening and evaluation, detailed description and purpose of the study was mentioned verbally to each participant and those subjects who agreed to participated in the study. The selected patient were randomly assigned to group $A(n=12 M / F)$, group $B(n=12 M / F)$ and group $C(n=12 M / F)$. The Selected subjects underwent indicated AFOs (SAFO, PLSAFO, and HAFO). Each intervention was given up to three months with wearing schedule 6-12 hours per day after which they were given specific interventions, along with demonstration of the correct way of using the intervention (SAFO, PLSAFO and HAFO).

\section{Intervention protocol}

Demographic data such as sex, age, height and weight were collected from the subjects. The subjects were screened and then subjects were randomly divided in three groups of 10 each who received different orthotic interventions. Subjects in Group A continued wearing the SOLID ankle foot orthosis while Subjects in Group B were provided with a POSTERIOR LEAF SPRING ankle foot orthosis and Group C were provided with HINGED ankle foot orthosis An ankle mold was made for each child upon initiation into the study by a single orthotics and the original mold was used to fabricate all three AFO configurations.

\section{Gait analysis}

The gait analysis system called CDG (Ultra flex Computer Demography Gait Analyzer) supplied by Infrotronics Medical Industrial Engineering was used for data collection. Each participant was asked to wear orthosis with shoes and then made to wrap the microcontroller called Ultra flex unit around the waist and a pair of foot sensors or CDG shoes of approximate size were put below the foot to collect force distribution. The cable of CDG shoes was connected to Ultra flex unit. The foot sensors data was digitally acquired at a sampling frequency of $100 \mathrm{~Hz}$ and stored in Memory stick of Ultra flex unit. The Ultra flex is a portable battery operated microcontroller unit storage facilities for off-line analysis. The gait data of all the subjects was evaluated in gait and biomechanics lab of National Institute for the Orthopedically Handicapped, Kolkata, India. All the dates were analyzed in CDG software and normalized with respect to the patients' physiological parameters. Prior to test there was $5 \mathrm{~min}$ of resting period for accommodation of the system. Two trials were given for the participant to get acquainted to the machine and walk in a straight line labeled of $1000 \mathrm{~cm}$. Patients were asked to walk with a self-selected comfortable pattern Gait parameters analyzed included velocity, stride length, step length, and cadence.

\section{Statistical analysis}

The data was managed on Excel spread sheet. Statistical analyses were made with software SPSS 16.0. This study consisted of three groups having SAFO, PLS AFO and HAFO. Each group has 10 subjects with Spastic Cerebral Palsy. Before the statistical analysis between the groups, the test of normality that is Shapiro-Wilk test and test of homogeneity that is Levene's test for equality of variance were used. A significant difference was defined when the p-value $<=0.05$, and results were given with a $95 \%$ confidence interval. To analyze the difference in the intervention in the groups, ANOVA post-hoc test was performed for interval data. Data were analyzed using one-way repeated measures analysis of variance (ANOVA) to determine if there were significant differences within the three assessment conditions (HAFO, PLS, and SAFO).

\section{Results and discussion}

In this study significant improvement found in PLSAFO in stride length in compare to SAFO ( $\mathrm{p}=0.006)$ and HAFO $(\mathrm{p}=0.012)$ although increases in stride length with AFO use are common, (Abel et al. 1998, White et al. ${ }^{27}$ This study significant increase in the cadence in PLSAFO than HAFO $(p=0.048)$ than SAFO $(p=0.004)$. This result shows that PLSAFO gives better improvement in spastic C.P and supported by study of White et al. ${ }^{27}$ Brodke et al. ${ }^{16}$, Knutson et al. ${ }^{17}$, Hesse et al. 1996; Carlson et al. ${ }^{28}$ Radtka et al. ${ }^{20}$ Abel et al. 1998. On the other hand, Buckon et al. ${ }^{18}$ found that the use of AFOs in $\mathrm{CP}$ children increased stride length, reduced cadence but did not significantly change walking velocity. In the study significant improvement found in PLSAFO in stride length in compare to SAFO $(p=0.006)$ and HAFO $(p=0.012)$. This supports the study of Buckon et al. ${ }^{18}$ but in present study it shows the improvement in velocity which is devoid from the result of Buckon et al. ${ }^{18}$ but supported by Shlomo 
hayek et al; White et al. ${ }^{27}$ and Dursun et al. which reported that the use of AFOs significantly increased walking velocity and stride length, but 'did not alter cadence. Previous studies Lehmann 1979, Lehmann et al. 1983, Mojica et al. 1988, Chen et al. 1999, Tyson and Thornton 2001, Gok et al. 2003, Shawn M Robin et al. 2006 have shown that wearing of plastic AFO increases walking speed, cadence and stride length of subjects. These findings were confirmed in the present study. Buckon et al. ${ }^{18}$ found statistically significant increases with AFO use in step and stride length, with a statistically significant decrease in cadence. Velocity was unchanged for this study's population.21 Brodke et al. ${ }^{16}$ reported a significant decrease in walking speed and cadence and no significant change in stride length in non-disabled children wearing AFOs compared with their walking barefoot. Whereas Carlson et al. ${ }^{28}$ reported that velocity and cadence were not statistically different when comparing children diagnosed with $\mathrm{CP}$ walking with AFOs with their walking with shoes but Stride length was considered statistically significant. Which also supported in this study, Radtka et al. ${ }^{20}$ assessed dynamic ankle-foot orthosis (DAFOs), solid AFOs, and barefoot walking in 10 children with spastic CP. They determined that both types of orthosis resulted in a statistically significant increased stride length and decreased cadence. Abel and colleagues (1998) found statistically significant improvements in velocity, stride length, and percent single limb support in participants with a primary diagnosis of $\mathrm{CP}$ using AFOs compared with their barefoot gait of children with CP. The Tables 1 \& (Graphs 1-7) shows a significant difference of application SAFO, PLS AFO \& HAFO in terms of step length, stride length, cadences and velocity. $\mathrm{P}=0.002$, so there is a significant differences of mean value in Step length on $0.30649 \pm 0.12115441$ (SAFO), $0.437 \pm 0.108412$ (PLSAFO) and $0.29549 \pm 0.11973$ (HAFO). $\mathrm{P}=0.003$ there is a significant differences of mean value in Stride length $0.562325 \pm 0.1348081$ (SAFO), $0.727775+0.084919$ in (PLSAFO), $0.57738+0.100791$ in (HAFO) $\mathrm{P}=0.005$ there is a significant differences of mean value in cadence 76.2+11.915 (SAFO), 94.6+13.68048 (PLSAFO), 81.5+9.204468 (HAFO). $\mathrm{P}=0.00 .2$, there is a significant differences of mean value in velocity $0.23 \pm 0.0537$ (SAFO), $0.324 \pm 0.62397$ (PLSAFO), $0.26 \pm 0.045947$ (HAFO). Step length: It was found significant difference of step length $(\mathrm{p}=0.020)$ with SAFO, PLS AFO, and HAFO individually but comparison of three AFO it was found that PLSAFO was more signicant $\mathrm{P}=0.047$ with $\mathrm{SAFO}$ and $\mathrm{p}=0.030$ with HAFO. This results finding support with author literature. Stride length: It was found significant difference of stride length $(\mathrm{p}=0.003)$ with SAFO, PLS AFO, and HAFO individually but comparison of three AFO it was found that PLSAFO was more signicant $\mathrm{P}=0.006$ with $\mathrm{SAFO}$ and $\mathrm{p}=0.012$ with HAFO. ${ }^{21,22 \text {, }}$
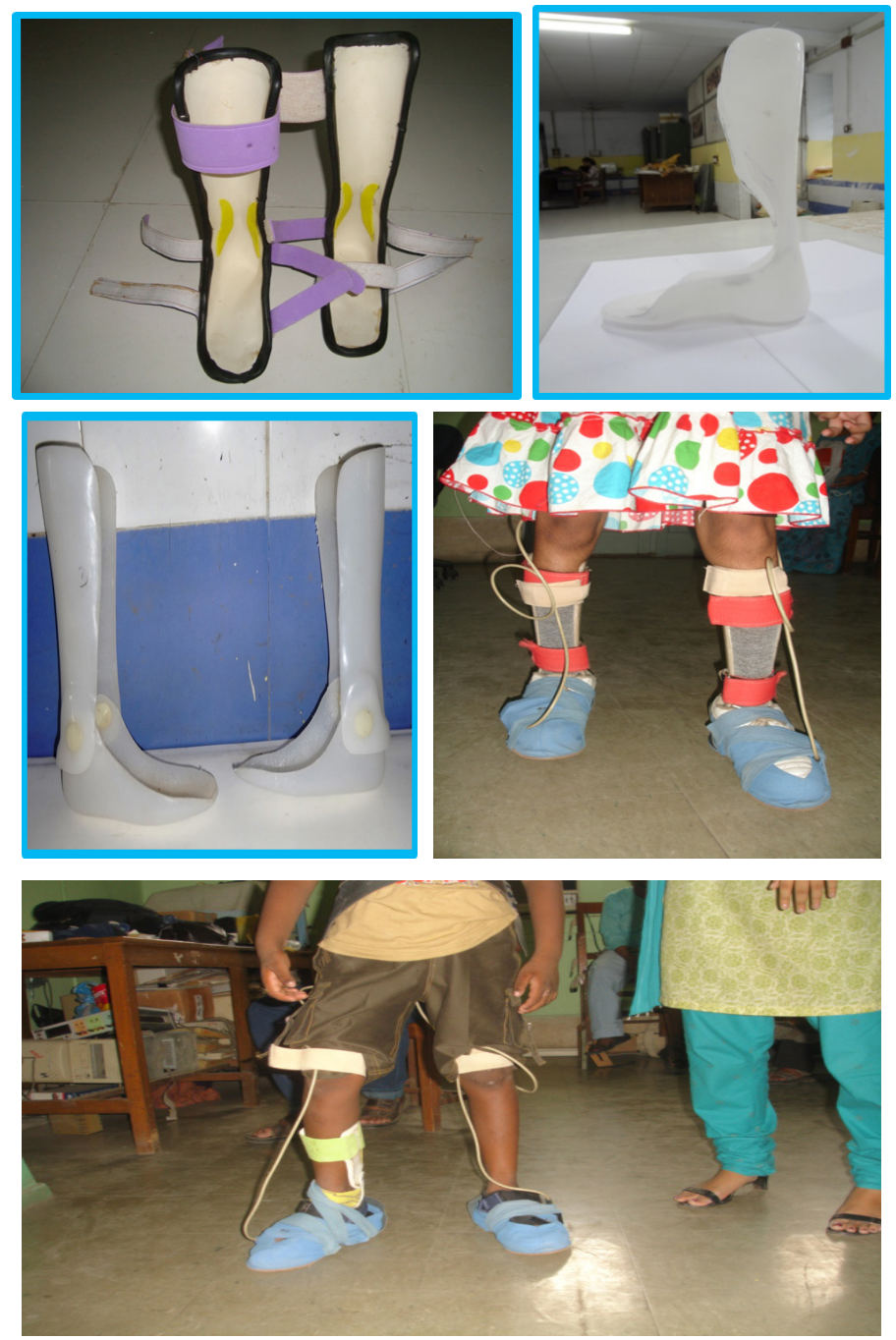

\begin{tabular}{llllll}
\hline Variable & SAFO Mean \pm SD & PLSAFO Mean \pm SD & H AFO Mean \pm SD & \multicolumn{2}{l}{ ANOVA } \\
\hline & & & & $\mathrm{F}$ & $\mathrm{P}$ \\
STEP LENGTH $(\mathrm{m})$ & $0.30649 \pm 0.1211544 \mathrm{I}$ & $0.437 \pm 0.1084 \mathrm{I2}$ & $0.29549 \pm 0.11973$ & 4.56 & 0.02 \\
STRIDE LENGTH $(\mathrm{m})$ & $0.562325 \pm 0.134808 \mathrm{I}$ & $0.727775 \pm 0.084919$ & $0.57738 \pm 0.10079 \mathrm{I}$ & 7.064 & 0.003 \\
CADANCE & $76.2 \pm 11.915$ & $94.6 \pm 13.68048$ & $81.5 \pm 9.204468$ & 6.503 & 0.005 \\
\hline VELOCITY $(\mathrm{m} / \mathrm{sec})$ & $0.23 \pm 0.0537$ & $0.324 \pm 0.62397$ & $0.26 \pm 0.045947$ & 7.777 & 0.002 \\
\hline
\end{tabular}

$\mathrm{P}=0.002$, so there is a significant differences of mean value in Step length on $0.30649 \pm 0.12115441$ (SAFO), 0.437 \pm 0.108412 (PLS AFO), 0.29549 \pm 0.11973 (HAFO). $\mathrm{P}=0.003$ significant differences OF mean value in Stride length $0.562325 \pm 0.1348081$ (SAFO), $0.727775 \pm 0.084919$ in (PLSAFO), $0.57738 \pm 0.100791$ in (HAFO). $\mathrm{P}=0.005$ significant differences $\mathrm{OF}$ mean value in cadence 76.2+11.915(SAFO), 94.6+13.68048 (PLSAFO), 81.5+9.204468 (HAFO), $\mathrm{P}=0.002$ so there is a significant differences $\mathrm{OF}$ mean value in velocity $0.23 \pm 0.0537$ (SAFO), $0.324 \pm 0.62397$ (PLSAFO), $0.26 \pm 0.045947$ (HAFO).

Velocity: It was found significant difference of velocity $(\mathrm{p}=0.002)$ with SAFO, PLS AFO, and HAFO individually but comparison of three AFO it was found that PLSAFO was more signicant $\mathrm{P}=0.002$ with SAFO and $\mathrm{p}=0.036$ with HAFO The AFOs did improved gait function for the cohort studied, as reflected by an increase in single 
limb stance, stride length, and velocity. Further investigation should focus on identifying other patient (Mark F. Abel, MD, Gregory A. Juhl, Christopher L. Vaughan, PhD, Diane L. Damiano, PhD, and PT) Buckon et al. ${ }^{18}$ The PLS was the most effective in normalizing gait parameters and improving stance phase knee motion in children with a tendency towards knee flexion in stance. Both the HAFO and PLS enhanced the performance in gait allowing children with spastic dieplegic to approach the functional level of their normally developing peers. ${ }^{29}$

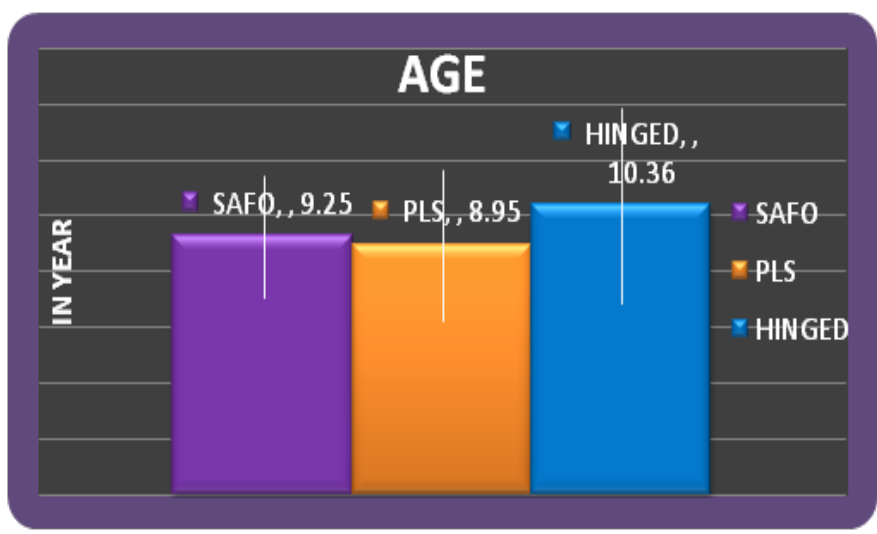

Graph I Age group of subjects having SAFO, PLS and hinged ankle foot orthosis.

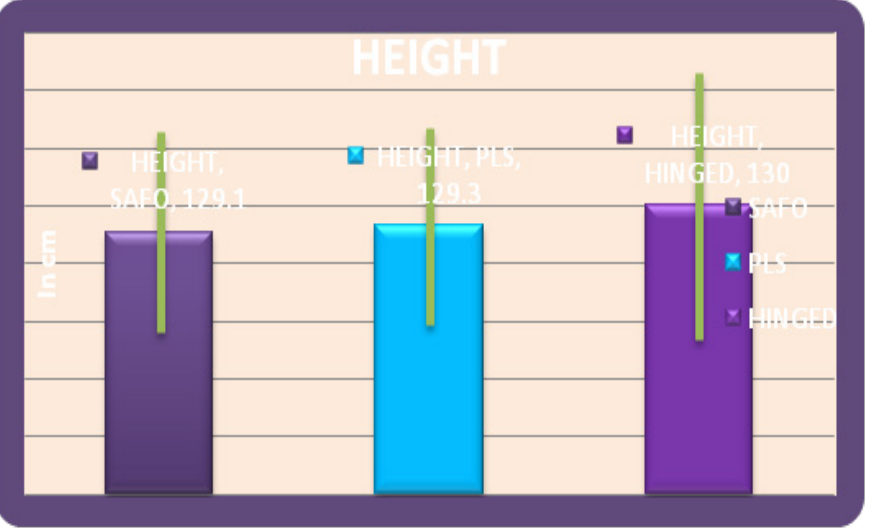

Graph II Difference in height in subjects with using SAFO,PLS and Hinged ankle foot orthosis.

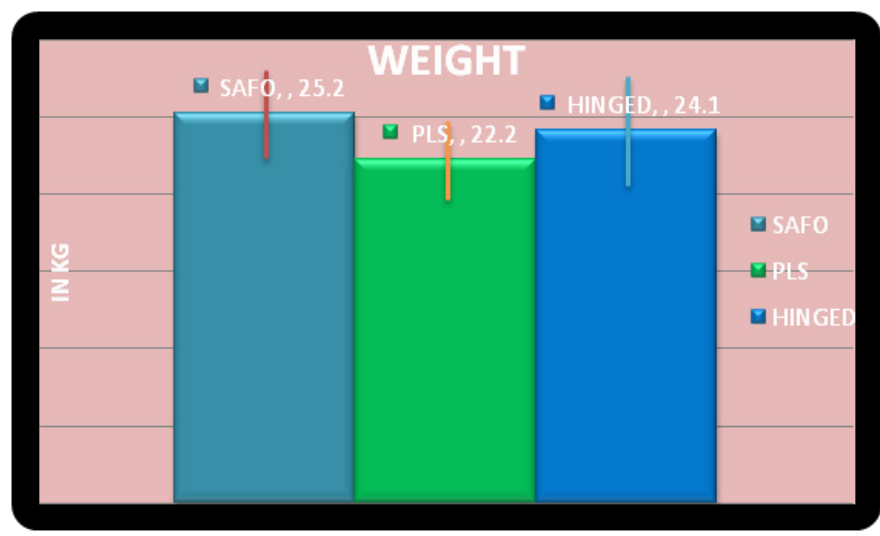

Graph III Difference in weight in subjects with using SAFO, PLS and Hinged ankle foot orthosis.

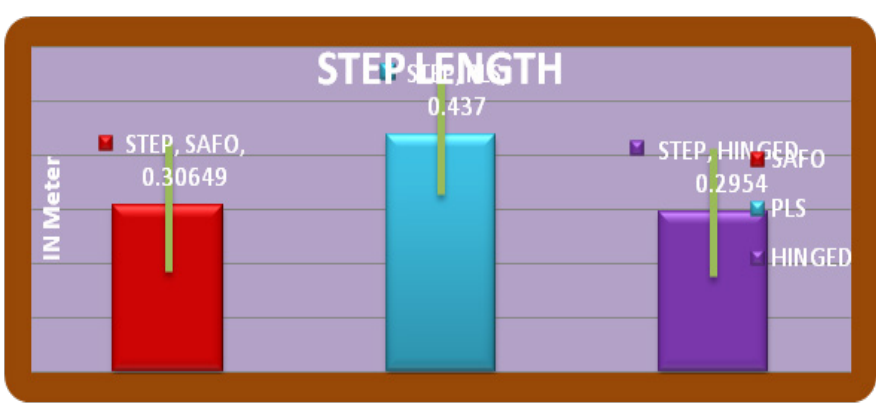

Graph IV Step length variation in SAFO, PLS and Hinged.

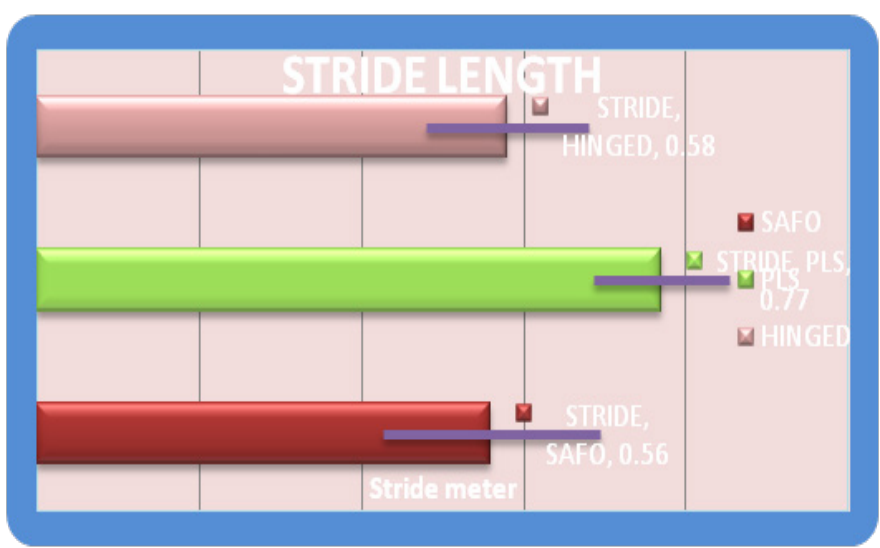

Graph V Stride length variation in three different groups.

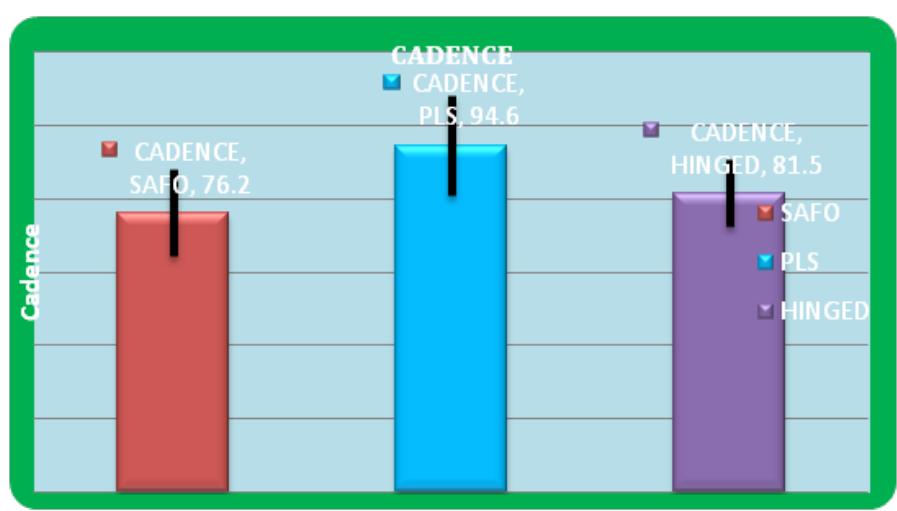

Graph VI Cadence variation in three groups of cerebral palsy subjects.

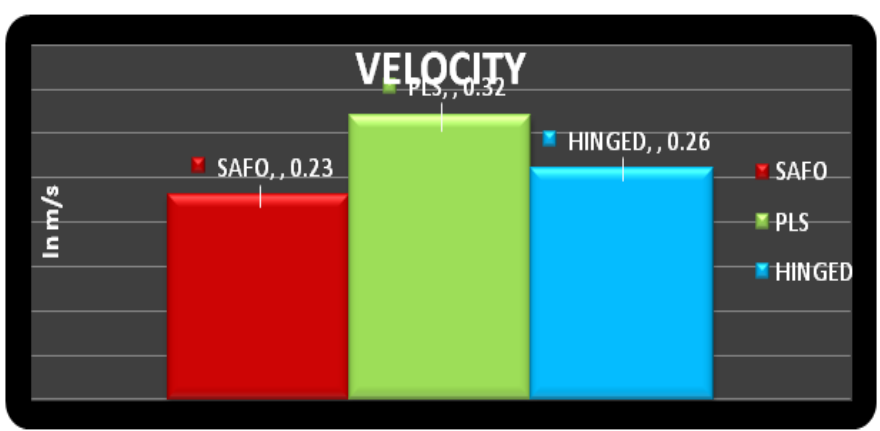

Graph VII Difference in velocity in subjects with SAFO, PLS and hinged ankle foot orthosis. 
Table I Demographic data

\begin{tabular}{llll}
\hline Subject & $\begin{array}{l}\text { SAFO } \\
\text { Mean } \pm \text { SD }\end{array}$ & $\begin{array}{l}\text { PLSAFO } \\
\text { Mean } \pm \text { SD }\end{array}$ & $\begin{array}{l}\text { HAFO } \\
\text { Mean } \pm \text { SD }\end{array}$ \\
\hline AGE & $9.25 \pm 2.2$ & $8.95 \pm 2.690415$ & $10.36 \pm 3.535$ \\
HEIGHT & $129.1 \pm 3.5103$ & $129.3 \pm 3.433495$ & $130.4 \pm 4.6236 \mathrm{I}$ \\
\hline WEIGHT & $25.2 \pm 2.78089$ & $22.9 \pm 2.5144$ & $24.1 \pm 3.541814$ \\
\hline
\end{tabular}

The mean age (Mean \pm SD) $9.25 \pm 2.2$ (SAFO), 8.95 \pm 2.690415 (PLSAFO), \& 10.36+3.535 (HAFO)

The mean height (Mean \pm SD) I 29. I+3.5 I03 (SAFO), I 29.3+3.433495(PLSAFO)

\& I30.4+4.6236I (HAFO)

The mean weight (Mean \pm SD) 25.2 2 2.78089 (SAFO), 22.9 $\pm 2.5 \mathrm{I} 44$ (PLSAFO) \& 24. I +3.541814 (HAFO)

\section{Conclusion}

The findings of the study that there were significant differences between the three design variants of AFO in improving gait parameters in subject with spastic dieplegic Cerebral Palsy. AFOs are typically prescribed to prevent deformity, contracture, support normal joint alignment, improve gait stability and provide variable range of motion. Orthotic management in spastic cerebral palsy is to produce a more normal gait pattern by positioning peripheral joints in a way that reduces pathological reflex patterns or by blocking pathological movement of the joint. Our current results show that the use of AFOs enhances the improvement in gait parameters i.e. step length, stride length, cadence and velocity. Limited sample size along with no other classification of $\mathrm{cp}$ is not considered and subjects chosen from single source may be the limitation in this study. The results show that the PLS AFO has more significant in comparison with SAFO and HAFO in all the parameters.

\section{Future recommendation}

The benefits of most orthotic interventions used in physical management regimens for children with cerebral palsy remain controversial. There continues to be significant variation in the orthotic management of children with CP among treatment centers as a result of conflicting treatment paradigms.

\section{Acknowledgement}

I would like to thank the patients for their unconditional support. I would also like to thank the National Institute for Orthopedically Handicapped in Kolkata India for the space for study and technical staff who actively participated.

\section{Conflict of interest}

None.

\section{References}

I. Thomas S Renshaw, Neil E Green, Paul P Griffin et al. Cerebral Palsy: Orthopaedic Management.J Bone Joint Surg Am. 1995; 77(10): 1590-1606.

2. Freeman JM. Nelson KB. Intrapartum Asphyxia and Cerebral Palsy. Pediatrics. I 988;82(2):240-249.

3. Nelson KB, Leviton A. How much of neonatal encephalopathy is due to birth asphyxia? Am J Dis Child. 1991;|45(II):|325-I331.
4. Nelson KB, Ellenberg JH. Antecedents of cerebral palsy. Multivariate analysis of risk. New England J Med. 1986;3I5(2):8I-86.

5. Bridget M Lawler, Jason Wening A. Functional Comparison of Solid and Articulated AFOs during Walking and Running In Children with Spastic Hemiplegic Cerebral Palsy. ACPOC; 2007.

6. Vogtle L, Sobus KM, Schuh LY, et al. Pain in adolescents and adults. ACCPDM 2005: Instructional course \#4.

7. Russman BS. Cerebral Palsy: Definition, Manifestations and Etiology. Turk J Phys Med Rehabil. 2002;48(2):4-6.

8. Pellegrino L, Dormans JP. Definitions, etiology and epidemiology of cerebral palsy' In Caring for Children with Cerebral Palsy A Team Approach. ERIC.1998:3-30.

9. Cans C, Dolk H, Platt MJ, et al. on behalf of SCPE Collaborative Group. Recommendations from the SCPE collaborative group for defining and classifying cerebral palsy. Dev Med Child Neurol Suppl. 2007; 109:35-38.

10. Rosenbaum P, Paneth N, Leviton A, et al. Definition and Classification Document, in The Definition and Classification of Cerebral Palsy. Dev Med Child Neurol Suppl. 2007;49:78-79.

II. Panteliadis CP. Classification' In Cerebral Palsy: Principles and Management. Panteliadis CP, Strassburg HM Stuttgart Thieme. 2004.

12. Andrew k, Berth, Peterson, et al. Cerebral Palsy. Lancet. 2004;363(9924): I619-I63I.

13. Kuban KC, Leviton A. Cerebral palsy. N Engl J Med. 1994;330(3): I88-195.

14. Charlton P, Ferguson D, Peacock C, et al. Preliminary clinical experience of a contracture correction device. Prosthetics and Orthotics International. 1999;23(2): 163-168.

15. Fiona Dobson, Meg E Morris, Richard Baker H. Kerr Graham Gait classification in children with cerebral palsy: A systematic review. Gait \& Posture. 2007;25(I): |40-152.

16. Brodke DS, Skinner SR, Lamoreux LW, et al. Effects of ankle-foot orthoses on the Gait of Children.J Pediatr Orthop. 1989;9(6):702-708.

17. Knutson LM, Clark DE. Orthotic devices for ambulation in children with cerebral palsy and myelomeningocele. Phys Ther. 1991;71(12):947-960.

18. Buckon CE, Thomas SS, Jakobson-Huston S, et al. Comparison of three ankle-foot orthosis configurations for children with spastic hemiplegia. Dev Med Child Neurol. 200 I;43(6):37I-378.

19. Buckon E. Comparison of three ankle-foot orthosis configurations for children with spastic diplegia, Developmental Medicine \& Child Neurology. 2004;46(9):590-598.

20. Radtka SA, Skinner SR, Dixon DM, et al. Comparison of Gait with Solid, Dynamic, and No Ankle-Foot Orthoses in Children With Spastic Cerebral Palsy. Phys Ther. 1997;77:395-409.

21. Condie D, Meadows C. Ankle-foot orthosis. In: Bowker P, editors. Bzomchanical Basis of Orthotic Manngeenlent. Oxford, United Kingdom: Butterworth-Heinemann Ltd; 1993:99-123.

22. Brehm MA, Harlaar J, Schwartz M. Effect of Ankle-Foot Orthoses on Walking Efficiency And Gait In Children with Cerebral Palsy. J Rehabil Med. 2008;40(7):529-534.

23. Papavasiliou A. Management of motor problems in Cerebral Palsy: A critical Update for the clinician. Eur J Paediatr Neurol. 2009; |3(5):387-396.

24. Chitra Sankar, Nandini Mundkur. Cerebral Palsy-Definition, Classification, Etiology and Early Diagnosis. Indian Journal of Pediatrics. 2005; 72(I0):865868. 
25. Rosen MG, Dickinson JC. The incidence of cerebral palsy. Am J Obste Gyneocol. 1992;167(2):417-423.

26. Winters TF, Gage JR, Hicks R. Gait patterns in spastic hemiplegia in children and young adults.J Bone Joint Surg Am. 1987;69(3):437-44I.

27. White $\mathrm{H}$, Jenkins J, Neace WP et al. Clinically prescribed orthoses demonstrate an increase in velocity of gait in children with cerebral palsy: a retrospective study, Developmental Medicine \& Child Neurology. 2002;44(4):227-232.
28. Carlson WE, Vaughan CL, Damiano DL. Et al. Orhtotic Management of gait in sapastic diplegia. Am J Phys Med Rehabil. 1997;76(3):219-225.

29. Tardieu C, Lespargot A, Tabary C, et al. For how long must the soleus muscle be stretched each day to prevent contracture? Developmental. Medicine \& Child Neurology. 1988;30(I):3-10. 